\title{
The Function of Volatile Organic Compounds (VOCs) Released from Cruciferous Crops Infested with Myzus persicae and Uninfested to Attract Parasitoids ${ }^{\dagger}$
}

\author{
Qasim Ahmed 1,*, Manjree Agarwal 2, Zahraa A. M. Alghadban 1, Ruaa Alobaidi ${ }^{3}$ and Yonglin Ren 2,* \\ 1 College of Agricultural Engineering Sciences, University of Baghdad, Al-Jadriya Campus, Baghdad 10071, \\ Iraq; qasim.h@coagri.uobaghdad.edu.iq (Q.A); zahraa.abd@coagri.uobaghdad.edu.iq (Z.A) \\ 2 College of Science, Health, Engineering and Education, Murdoch University, South Street, Murdoch 6150, \\ WA; m.agarwal@murdoch.edu.au (M.A.); y.ren@murdoch.edu.au (Y.R) \\ 3 College of Pharmacy, Al-Mustansiriyah University, Al-Qadisyia, Baghdad 10052, Iraq; ruaaloli@gmail.com \\ * Correspondence: qasim.h@coagri.uobaghdad.edu.iq (Q.A); y.ren@murdoch.edu.au (Y.R.) \\ + Presented at the 1st International Electronic Conference on Entomology (IECE 2021), 1-15 July 2021; \\ Available online: https://iece.sciforum.net/.
}

Citation: Ahmed, Q.; Agarwal, M.; Alghadban, Z.A.M.; Alobaidi, R.; Ren, Y. The Function of Volatile Organic Compounds (VOCs) Released from Cruciferous Crops Infested with Myzus persicae and Uninfested to Attract Parasitoids, in Proceedings of the 1st International Electronic Conference on Entomology, 1-15 July 2021, MDPI: Basel, Switzerland, doi:10.3390/IECE-10535

Published: 1 July 2021

Publisher's Note: MDPI stays neutral with regard to jurisdictional claims in published maps and institutional affiliations.

Copyright: () 2021 by the authors. Submitted for possible open access publication under the terms and conditions of the Creative Commons Attribution (CC BY) license (http://creativecommons.org/licenses /by/4.0/).

\begin{abstract}
The green peach aphid, Mysuz persicae is a parasitic aphid and a commonly found polyphagous insect. It can cause direct and indirect damage to many plant families, including cruciferous crops, by feeding on plant sap and transmitting plant pathogens. The aphid infestation can trigger the host plant, such as cabbage to release different volatile organic compounds (VOCs) and parasitoids can use some of these compounds as chemical markers to distinguish their hosts. Some compounds were discovered in both infested and uninfested cabbage using headspace solid microextraction (SPME) coupled with GC-MS technology. According to the GC-MS report, VOCs released from infested and uninfested cabbage plants varied quantitatively and qualitatively. In a Y-tube olfactometer bioassay, M. persicae attracts both infested and uninfested plants, and the parasitoids Aphelinus abdominalis and Aphidus colemani prefer infested plants to uninfested plants.
\end{abstract}

Keywords: VOCs; cabbage; GC-MS; SPME; olfactometer; Mysuz persicae; parasitoids; Aphelinus abdominalis; Aphidus colemani

\section{Introduction}

Myzus persicae (Hemiptera: Aphididae) is a serious insect with a worldwide distribution, including Australia [1,2]. It has caused damage to hundreds of agricultural crops in more than 66 families. The aphid lives primarily in the tissues of young plants, resulting in smaller leaves, slower plant growth, and lower yield [3]. M. persicae is a widespread cruciferous crop pest insect that feeds on plant sap, causing yellowing and curling of plant leaves. Honeydew excretion by aphids also affects plant photosynthesis and promotes

fungal growth [4]. Different species of aphids, such as turnip aphid Lipaphis erysimi, cabbage aphid Brevicoryne brassicae and green peach aphid M. persicae commonly attack cabbage and broccoli plants and economically damage these crops [5].

Pesticides are important for crop pest control. They are commonly used in horticultural systems, but they can result in the appearance of secondary pests rather than primary pests, pesticide resistance, environmental pollution, and non-target species impacts [6,7]. As a result, new pest control methods must be created. Aphid parasitoids belonging to the Braconidae and Aphelinidae families are important in biological control because they can destroy large numbers of aphids [8,9]. Aphid natural enemies can delay population development, and wasp parasitoids have been shown to be useful in biological aphid management [10]. Plant volatile organic compounds (VOCs) affect insect communication 
and plant defense, both of which are important in plant-insect interactions [11]. When sucking insect pests like the green peach aphid feed on the plant, one of the plant's responses is to emit odors in the form of volatile organic compounds (VOCs). Since parasitoids use VOCs to locate their hosts, they are important in plant-insect interactions [12]..

This study aims to distinguish between healthy and M. persicae infested cabbage and broccoli plants, and then to investigate the responses between $M$. persicae and its parasitoids A. colemani and A. abdominalis using the Y-tube ol-factometer with infested and unifested cruciferous plants. Understanding the factors that affect parasitoid attraction is a key factor for control of green peach aphids and development of novel biological management strategies.

\section{Materials and Methods}

\subsection{Experimental plants}

Cabbage (Brassica oleracea L. var. capitata) and broccoli (Brassica oleracea L. var. italica) seeds were sown in a $90 \mathrm{~mm}$ square pot filled with potting soil mixture (Richgro Regular Potting Mix, NSW, Australia) and cultivated in a greenhouse at $23-25^{\circ} \mathrm{C}, 60-70 \%$ relative humidity, at L16:D8 light cycle. Plants were grown to the level of 7-9 leaves in a glasshouse and used in all experiments.

\subsection{Insect culture}

For the experiments, M. persicae was obtained from the Western Australian (the Department of Primary Industries and Regional Development, Entomology Branch). The aphid culture was maintained on potted cabbage seedlings in a greenhouse that were placed into large cages $(210 \mathrm{~cm} \times 90 \mathrm{~cm})$ covered in anti-aphid mesh and provided with a control light system set at L16: 8D photoperiod, at a glasshouse temperature of $23-25^{\circ} \mathrm{C}$.

Aphidus colemani (Hymenoptera, Braconidae) and Aphelinus abdominalis (Hymenoptera, Aphelinidae) were commercially obtained from Biological Services (South Australia) as mummies and maintained on potted cabbage plants infested with M. persicae as hosts.

\subsection{Olfactometer bioassays}

The responses of $M$. persicae and its two species parasitoids, A. colemani and A. abdominalis, to each of the following pairs of plant treatments were measured using a glass $\mathrm{Y}$ tube olfactometer. The aphid responses were tested using three different conditions: (1) infested (cabbage plants infested with M. persicae) versus clean (filter) air; (2) non-infested versus clean air; and (3) infested versus non-infested plants. The treatment of plants was used to monitor parasitoid wasps, A. colemani and A. abdominalis. Bioassays were conducted to compare parasitoid's olfactory responses to VOCs released by cruciferous plants.

A glass Y-tube olfactometer with a $7 \mathrm{~cm}$ arm length and $2 \mathrm{~cm}$ internal diameter, ground glass suitable for purging air at $200 \mathrm{~mL} / \mathrm{min}$ through each arm, operated by an air flow meter (SCFH AIR, Dwyer Instruments, Michigan City, IN 46360, USA) [13]. A 2 L desiccator was attached to each arm hose. At the end of each arm, a couple of blend VOCs [released from various plant (infested and uninfested plants)] were presented in a sealed glass chamber. Until the treatment plant could be introduced, the compressed air was filtered with activated charcoal and passed through two glass chambers, and then the air was passed through the olfactometer system. The olfactometer was left to stablise for 15 minutes after assembly and before conducting each test to flush out all remaining residues and clean the system [14].

\subsection{Statistical analysis}


The data of the Y-tube olfactometer bioassays were analyzed for preference (aphid M. persicae and their parasitoids A. colemani and A. abdominalis choice between two treatments tested) using the Chi-Square goodness of fit test by using SPSS software version 24.0.

\section{Results}

The aphids M. persicae and their parasitoids A. colemani and A. abdominalis responded to the uninfested and infested plants (cabbage or broccoli) by 30 individual aphids and 15 individuals per duplicate of parasitoid in laboratory studies using Y-tube olfactometer bioassays.

According to the findings, green peach aphids in cabbage and broccoli were substantially more responsive to VOCs produced by infested plants than to clean air. The proportion of aphids attracted to the infested plant was $80 \%$ for cabbage plants versus $7 \%$ for clear air, and $70 \%$ for broccoli plants versus $10 \%$ (Chi-Square $\left(\chi^{2}\right)=18.61, \mathrm{df}=1$ and $P<0.0005$ for the cabbage and $\chi^{2}=14.44, \mathrm{df}=1$ and $P<0.0005$ for the broccoli) (Figure 1 ). The results revealed that $M$. persicae had a strong preference for both cabbage and broccoli, with the healthier plants attracting them rather than clean air.

The number of aphids attracted to the cabbage was $75.56 \%$ versus $3 \%$ for the broccoli and $84 \%$ versus $7 \%$ for the cabbage $\left(\chi^{2}=20.16, \mathrm{df}=1\right.$ and $P=0.0005$ for the cabbage and $\chi^{2}=$ $19.59, \mathrm{df}=1$ and $P=0.0005$ for the broccoli). Although the results showed that aphids were slightly more attractive to the infested cabbage than the healthy plant, the results also showed that broccoli volatiles had little impact. The percentage of aphid attracted to infested plants were $63 \%$ and $57 \%$ for cabbage and broccoli plants, respectively, compared to $26.67 \%$ and $30 \%$ for healthy plants for cabbage and broccoli plants, respectively $\left(\chi^{2}=\right.$ $4.48, \mathrm{df}=1$ and $P<0.034$ for the cabbage and $\chi^{2}=2.46, \mathrm{df}=1$, and $P=0.117$ for the broccoli).

The parasitoids A. colemani and A. abdominalis were attracted to volatiles produced by plants in experiments where they were given a choice between healthy and infested plants. As opposed to clean plants, both A. colemani and A. abdominalis were slightly more attracted to volatiles from infested plants by green peach aphid (Figure 2). According to the statistical study, for all parasitoids A. colemani and A. abdominalis, the rate of parasitoid attraction was $93.33 \%$ and $100 \%$ towards the infested cabbage plant, respectively, versus $7 \%$ and $20 \%$ towards the clean air $\left(\chi^{2}=11.26, \mathrm{df}=1, P=0.001\right.$ for $A$. colemani and $\chi^{2}=4.57$, $\mathrm{df}=1$ and $P=0.033$ for $A$. abdominalis). Both parasitoids were significantly directed to the infested plant. However, there were no variations in attracted wasp responses to odors emitted from a healthy plant versus clean air, and both parasitoids A. colemani and $A$. abdominalis had no responses to the health plant odor versus clean air (both parasitoids showed significantly no responses to the treatments).

On a percentage basis, $4.44 \%$ of $A$. colemani wasps and $7 \%$ of $A$. abdominalis were attracted to volatiles released from uninfested plants, compared to $7 \%$ for all parasitoids heading for clean air treatment. While the percentage of parasitoids with no responses was $88.86 \%$ and $86.66 \%$ for both $A$. colemani and $A$. abdominalis, respectively $\left(\chi^{2}=19.20, \mathrm{df}=\right.$ 2 and $P=0.001$ for $A$. colemani and $\chi^{2}=19.20, \mathrm{df}=2$ and $P=0.001$ for $A$. abdominalis). When given the alternative between healthy and infested cabbage plants, A. colemani and A. abdominalis parasitoids were slightly more attracted to volatiles produced by infested plants. In terms of proportion, $86.67 \%$ of $A$. colemani and $100 \%$ of $A$. abdominalis were attracted to infested cabbage, compared to $9 \%$ of $A$. colemani and $0 \%$ of $A$. abdominalis attracted to healthy plants $\left(\chi^{2}=10.28, \mathrm{df}=1\right.$ and $P=0.001$ for $A$. colemani and $\chi^{2}=12.25, \mathrm{df}=1$ and $P=0.0005$ for A. abdominalis). 


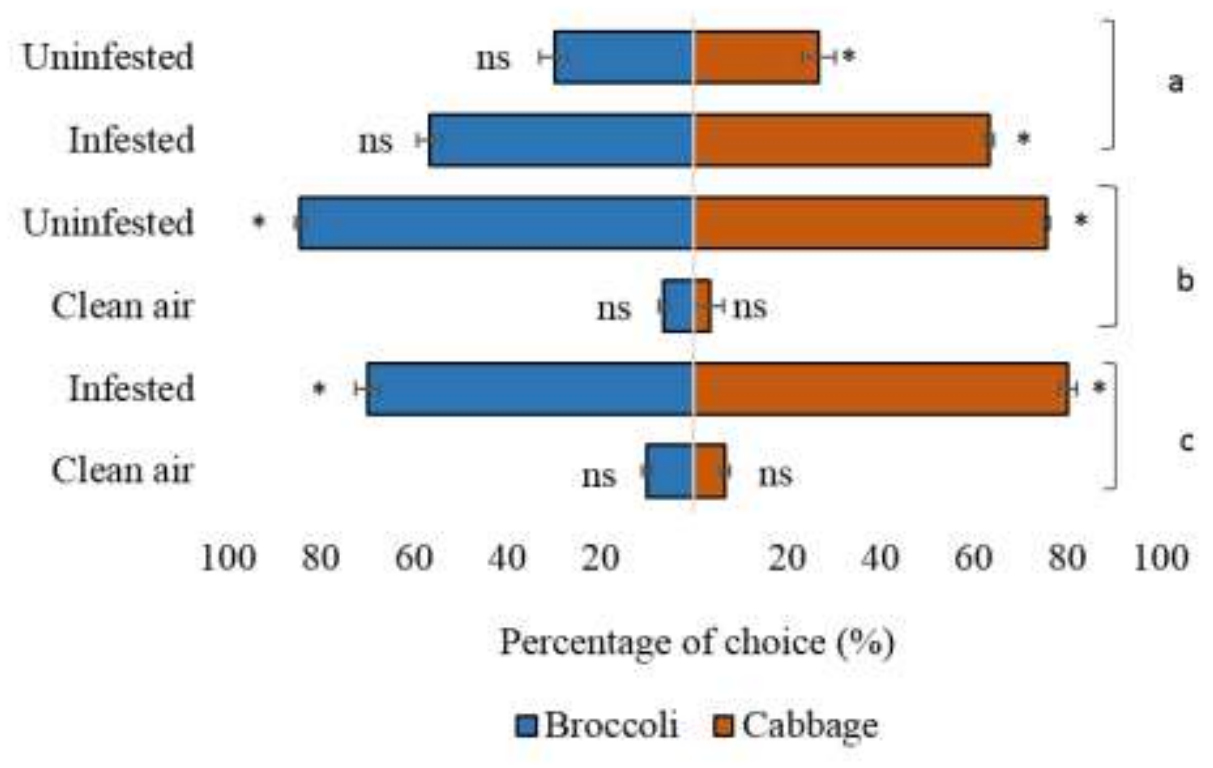

Figure 1. Olfactory response of green peach aphid M. persicae in Y-tube olfactometer experiments to volatiles released from infested and uninfested cabbage and broccoli (a) uninfested versus infested plants (b) uninfested versus clean air (c) infested versus clean air. All treatments presented with standard deviation (SD) bar. Asterisks $\left(^{*}\right)$ indicates significant difference $P<0.05$ (Chi-square test).

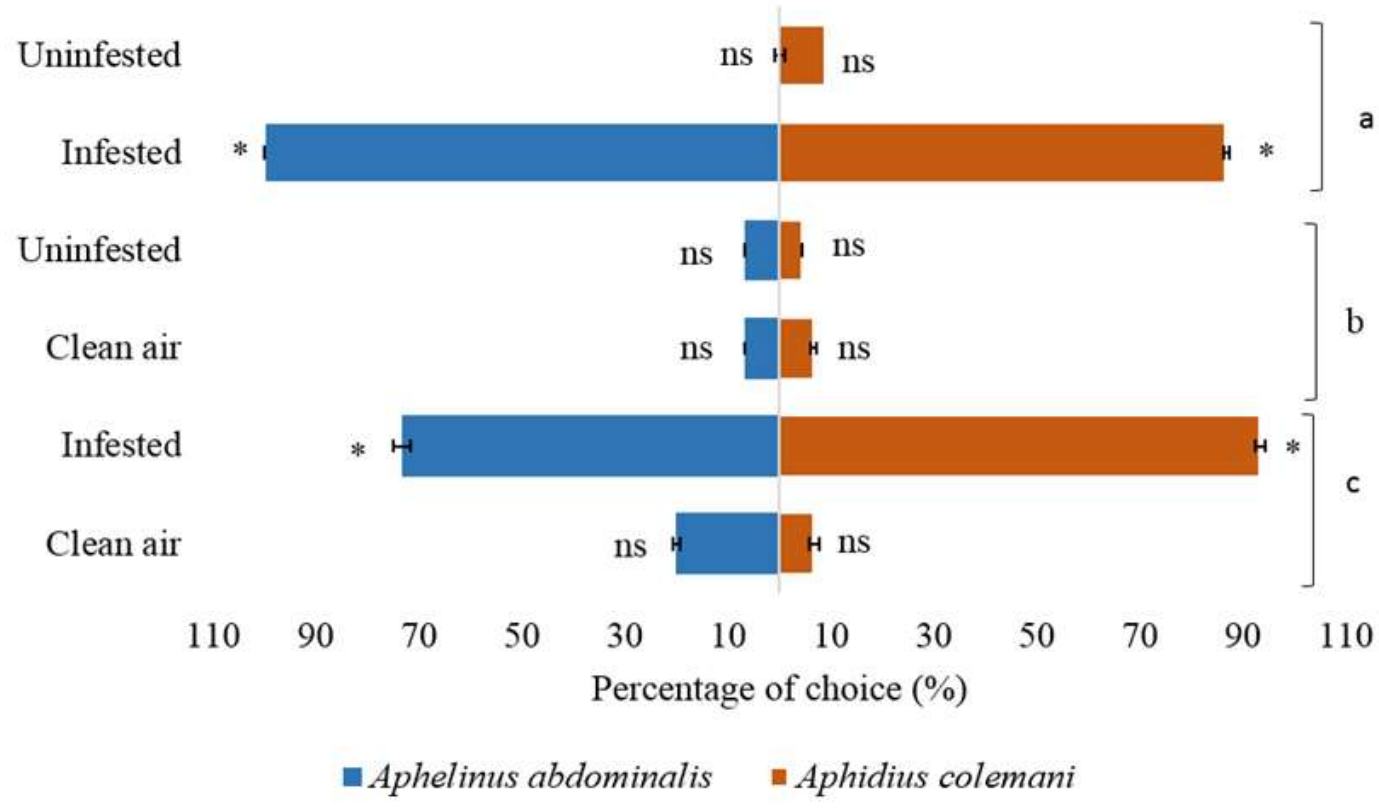

Figure 2. Olfactory response of two parasitoids Aphidius colemani and Aphelinus abdominalis in Y-tube olfactometer experiments to volatiles released from infested and uninfested cabbage B. oleracea (a) uninfested versus infested plants (b) uninfested versus clean air (c) infested versus clean air. All treatments presented with standard deviation (SD) bar. *indicates significant difference $\mathrm{P}<0.05$ (Chi-square test). 


\section{Discussion}

Aphids M. persicae and parasitoids A. colemani and A. abdominalis were affected and attracted to volatiles produced by cruciferous plants, according to the results of Y-tube olfactometer bioassays. Volatiles from aphid-infested plants were much preferred by these wasps, and they were attracted to them. The use of a Y-tube olfactometer to measure the reaction of the aphid M. persicae to the host plant, B. oleracea var capitata and B. oleracea var italica, revealed that M. persicae were affected by the volatiles released by cabbage and broccoli, and were significantly attracted to both healthy and infested plants when compared with clean air choice.

Aphids can identify their host visually and chemically, such as by chemical, color, size, and form, and this may be a helpful guide for attracting aphids. This finding backs up previous research $[15,16]$ that showed aphids use plant odor as well as visual signals to locate their host plants. Furthermore, in studies measuring plant odor against aphids and their host-finding potential, the attraction of aphids to plant volatiles using an olfactometer has been documented [15,17]. According to our findings, aphids were responsive to both damaged and healthy plants. Plant volatile compounds will increase in response to feeding [18,19].

According to the results of the olfactometer tests, the parasitoids respond to plant volatiles, and A. colemani and A. abdominalis respond to the odor produced by infested plants. When the parasitoids offered to a clean air and infested plant treatments, both parasitoids are greatly responsive to plant volatiles. This finding was in agreement with Kalule and Wright's findings [20]. The parasitoids' preference for clean air and uninfested cabbage displayed no response of parasitoid attraction, whereas the parasitoids noted a statistically significant non-response. According to Kalule and Wright [20], parasitoids are attracted to the infested plant and attack aphids that feed on the same plant as the source of the mummy provided. The parasitoids A. colemani and A. abdominalis responded to the infested B. oleracea by choosing the volatiles produced by the infestation of aphids. Both parasitoids have strong reactions to aphid-infested plants. The findings are consistent with those of Kalule and Wright [20], who found that parasitoid A. colemani was attracted to volatiles produced by Brassica juncea and favored green peach aphid M. persicae damaged plants over the damaged of plants by Plutella xylostella caterpillar. The parasitoids of A. colemani and A. abdominalis lay eggs in M. persicae's body, and immature stages develop within the hosts, ultimately killing them by feeding the wasp larva inside aphid's body. The parasitoid pupates within the aphid's mummy, and it emerges as an adult. Many parasitoids, including A. colemani and A. abdominalis, are thought to rely on odors emitted from infested plants as a reaction to aphid feeding to identify and locate hosts. As a result, as Hatano et al. [16] demonstrate, certain aphid's parasitoids effectively search for infested plants where aphids would be present.

\section{Conclusion}

Using an olfactorometer, the preferences of A. colemani and A. abdominalis of infested plants with $M$. persicae were compared to uninfested plants and clean air. The findings revealed that parasitoids can distinguish between infested cabbage and broccoli and react to the plant odor in a significant way. As a result, we conclude that aphid parasitoids can locate infected plants and use plant odor to identify aphids on the plant. Since parasitoids will first look for infested plants before looking for aphids, it is possible that the natural enemies' search for aphid infestation will begin before attracting them to the uninfested plants.

Author Contributions: Conceptualization, Q.A., M.A., Z.A., R.A. and Y.R.; data curation, Q.A.; investigation, Q.A.; methodology, Q.A., Z.A. and R.A.; project administration, Q.A. and Y.R.; resources, Q.A. and Y.R.; supervision, M.A. and Y.R.; validation, Q.A., M.A., and Y.R.; writing original draft: Q.A. Writing-review and editing: Q.A., M.A., and Y.L. 
Funding: This research received no external funding.

Informed Consent Statement: Not applicable.

Acknowledgments: We would like to thank the Iraqi government and the University of Baghdad for supporting to the first author and sponsored a Ph.D. scholarship. We also appreciate the support of Murdoch University Postharvest Biosecurity and Food Safety Laboratory, and thanks to technician's team in the laboratory.

Conflicts of Interest: The authors declare no conflict of interest.

\section{References}

1. Kim, J. H.; Jander, G., Myzus persicae (green peach aphid) feeding on Arabidopsis induces the formation of a deterrent indole glucosinolate. The Plant J 2007, 49, 1008-1019.

2. Valenzuela, I.; Hoffmann, A. A. Effects of aphid feeding and associated virus injury on grain crops in Australia. Austral Entomol 2015, 54, 292-305.

3. Yoon, C.; Seo, D. K.; Yang, J. O.; Kang, S. H.; Kim, G. H., Attraction of the predator, Harmonia axyridis (Coleoptera: Coccinellidae), to its prey, Myzus persicae (Hemiptera: Aphididae), feeding on Chinese cabbage. J Asia-Paci Entomol 2010, 13, 255-260.

4. Amarawardana, L.; Bandara, P.; Kumar, V.; Pettersson, J.; Ninkovic, V.; Glinwood, R., Olfactory response of Myzus persicae (Homoptera: Aphididae) to volatiles from leek and chive: potential for intercropping with sweet pepper. Acta Agri Scandinavica Sec B Soil and Plant Sci 2007, 57, 87-91.

5. Liu, T. X.; Sparks Jr, A. N., Aphids on cruciferous crops: identification and management. Texas AgriLife Exten 2001, (B-6109), 111.

6. Anstead, J. A.; Williamson, M. S.; Denholm, I., Evidence for multiple origins of identical insecticide resistance mutations in the aphid Myzus persicae. Insect Bioch Mole Bio 2005, 35 (3), 249-256.

7. Nauen, R.; Denholm, I., Resistance of insect pests to neonicotinoid insecticides: current status and future prospects. Arch insect bioch physio 2005, 58 (4), 200-215.

8. Reed, H.; Tan, S.; Haapanen, K.; Killmon, M.; Reed, D.; Elliott, N., Olfactory responses of the parasitoid Diaeretiella rapae (Hymenoptera: Aphidiidae) to odor of plants, aphids, and plant-aphid complexes. J Chem Ecol 1995, 21 (4), 407-418.

9. Takemoto, H.; Takabayashi, J., Parasitic wasps Aphidius ervi are more attracted to a blend of host-induced plant volatiles than to the independent compounds. J Chem Ecol 2015, 41 (9), 801-807.

10. Goh, H. G.; Kim, J. H.; Han, M. W., Application of Aphidius colemani Viereck for control of the aphid in greenhouse. J Asia-Paci Entomol 2001, 4 (2), 171-174.

11. Guerrieri E, D. M., Aphid-plant interactions. J Plant Intera 2008, 3, $223-232$.

12. De Farias, A. M.; Hopper, K. R., Responses of female Aphelinus asychis (Hymenoptera: Aphelinidae) and Aphidius matricariae (Hymenoptera: Aphidiidae) to host and plant-host odors. Enviro entomol 1997, 26 (4), 989-994.

13. Saad, K. A.; Roff, M. M.; Hallett, R. H.; Idris, A., Aphid-induced defences in chilli affect preferences of the whitefly, Bemisia tabaci (Hemiptera: Aleyrodidae). Sci repor 2015, 5, 13697.

14. Pope, T.; Girling, R.; Staley, J.; Trigodet, B.; Wright, D.; Leather, S.; Van Emden, H.; Poppy, G., Effects of organic and conventional fertilizer treatments on host selection by the aphid parasitoid Diaeretiella rapae. J Appl Entomol 2012, 136 (6), 445-455.

15. Döring, T. F., How aphids find their host plants, and how they do not. Ann appl bio 2014, 165 (1), 3-26.

16. Hatano, E.; Kunert, G.; Michaud, J.; Weisser, W. W. Chemical cues mediating aphid location by natural enemies. Euro J Entomol $2008,105,797$.

17. Verheggen, F. J.; Haubruge, E.; De Moraes, C. M.; Mescher, M. C., Aphid responses to volatile cues from turnip plants (Brassica rapa) infested with phloem-feeding and chewing herbivores. Arthro Plant Intera 2013, 7 (5), 567-577.

18. Hopkins, D. P.; Cameron, D. D.; Butlin, R. K., The chemical signatures underlying host plant discrimination by aphids. Sci repor 2017, 7 (1), 8498.

19. Züst, T.; Agrawal, A. A., Mechanisms and evolution of plant resistance to aphids. Nature plants 2016, 2 (1), 15206.

20. Kalule, T.; Wright, D., The influence of cultivar and cultivar-aphid odours on the olfactory response of the parasitoid Aphidius colemani. J Appl Entomol 2004, 128 (2), 120-125. 